INVESTIGACIONES

EN HISTORIA DE LA

SALUD PUBLICA

Rev Chil Salud Pública 2013

Vol 17 (1): 70-77

\section{Historias del Hospital San Vicente de Paul; Hoy Hospital Clínico José Joaquín Aguirre (Primera parte)}

\author{
The History of San Vicente de Paul Hospital, today known \\ as José Joaquín Aguirre Clinical Hospital (First Part)
}

Durante un recorrido patrimonial por la Facultad de Medicina y el Hospital José Joaquin Aguirre el año pasado, conocí a una arquitecto que me explicó detalles de la Capilla del Antiguo Hospital y de la fachada del actual Hospital San José. En el diálogo ella me conto de una historia inédita escrita por su padre y luego hablamos de la posibilidad de publicar ese manuscrito ahora póstumo. La intención original del texto sugiere el formato de libro, pero quisimos incluirlo aunque fuera en dos partes, como un reconocimiento al esfuerzo de nuestro colega y al cariño patrimonial de una hija. Agradecemos toda la paciencia, confianza y colaboración de Paula Ahumada.

El Editor

Para muchos médicos, chilenos y extranjeros, este antiguo hospital fue su "casa» y su «cuna». Miles de enfermos de Santiago y provincias fueron atendidos en sus salas.

Su historia está ligada al desarrollo de la Medicina Chilena y sobre todo a la enseñanza. Alumnos y profesores pasaron por sus patios dejando su recuerdo. Fundado a fines del siglo XIX, tendrá una vida activa y docente durante todo el 1900, hasta 1952, fecha en que se traslada al Hospital José Joaquín Aguirre, cuya obra gruesa esperó por años ser terminada y ocupar el lugar actual en la calle Santos Dumont.

Para la generación de mis hijos y nietos, ya no saben ni de su ubicación en el pasado, ni de su existencia. Es por eso que hemos querido traer algunos recuerdos de él. Tengo muchos y mucha gratitud por él, porque llegué como estudiante de Medicina de 3er año en 1937. Aprendí los primeros pasos de la medicina, como alumno, interno y como médico. En él además, descubrí lo que sería mi especialidad y mi futuro en la Cardiología, que me daría después tantas satisfacciones.

Para nosotros, alumnos, cuando recién llegamos, fue una alegría, porque con nuestro entusiasmo de ser "médicos un día» y atender enfermos, nos encontrábamos con un hospital enorme y nos asomábamos así a la «enfermedad» y a los «pacientes».

Veníamos de la Universidad Católica, que no tenía hospital en esa época. Ya habíamos pasado todos los estudios teóricos de los primeros dos años. Ahora estábamos frente a la Escuela de Medicina y a su hospital paralelo, con nuevos alumnos, enfermos y camas. 


\section{EL HOSPITAL}

El hospital nació como una necesidad docente, al lado de las edificaciones de la Escuela de Medicina de la Universidad de Chile, fundada ya en 1889 en la zona norte de Santiago, en la calle Independencia.

Su imponente edificio, con sus bellas columnas de entrada, sus jardines alrededor, sus palmeras, ofrecían acogida a miles de alumnos chilenos y extranjeros. Ocuparía más o menos media cuadra, desde la esquina de Independencia con Zañartu.

Imposible imaginar sus numerosas secciones, salas de clases, laboratorios, auditorios, uno central para 300 alumnos. Por más de un siglo, esta Escuela cumplió sus funciones en este edificio de estilo europeo, elegante y sobrio.

Un incendio, en 1948, destruyó gran parte de su edificación, laboratorios, museos, biblioteca y salas de clases. Pasado el dolor colectivo de profesores y alumnos, la Escuela fue reconstruida en su edificio actual, siempre imponente. Su construcción ahora fue más cargada al cemento y a los grandes espacios, pero conservando la estructura fundamental.

El edificio del Hospital San Vicente de PauI, se construyó a continuación de la Escuela de Medicina, a fines del siglo XIX y comienzos del XX, en la calle Independencia, al norte de Santiago.
La calle Independencia era una amplia avenida, que partía al norte del Río Mapocho, cerca de la Estación de Ferrocarril del mismo nombre. Una doble línea de tranvía, de ida y de vuelta, ocupaba la parte central. Era la línea «36», más moderna que los del resto de la ciudad en esos momentos. Era la línea «Matadero-Palma», indicando su comienzo y término. Su clientela iba variando según los barrios que iba atravesando. Sus asientos, con un petate de fibra fina, le daban un carácter de elegancia, diferente a los de madera del resto de Santiago. Es curioso que su limpieza se mantuviera a pesar de tanto uso y de personas tan diferentes. Su frecuencia y ritmo, no permitía grandes esperas.

El edificio del Hospital, estaba a continuación de la Escuela de Medicina, en la parte sur de la cuadra, y junto con los edificios posteriores de los Servicios de Urgencia y Pensionado llegaría hasta el mismo Santos Dumont.

La Facultad de Medicina, con los profesores de la época, donde algunos, además de ser buenos médicos estaban en la política nacional y eran suficientemente influyentes, unieron sus esfuerzos con los Servicios Estatales, llamados de Beneficencia Pública y junto a donaciones pudieron indiciar la construcción del San Vicente de Paul.

La obra fue encargada a arquitectos franceses o alemanes, quienes pusieron su experiencia de los hospitales europeos. Esto no cabe duda cuando

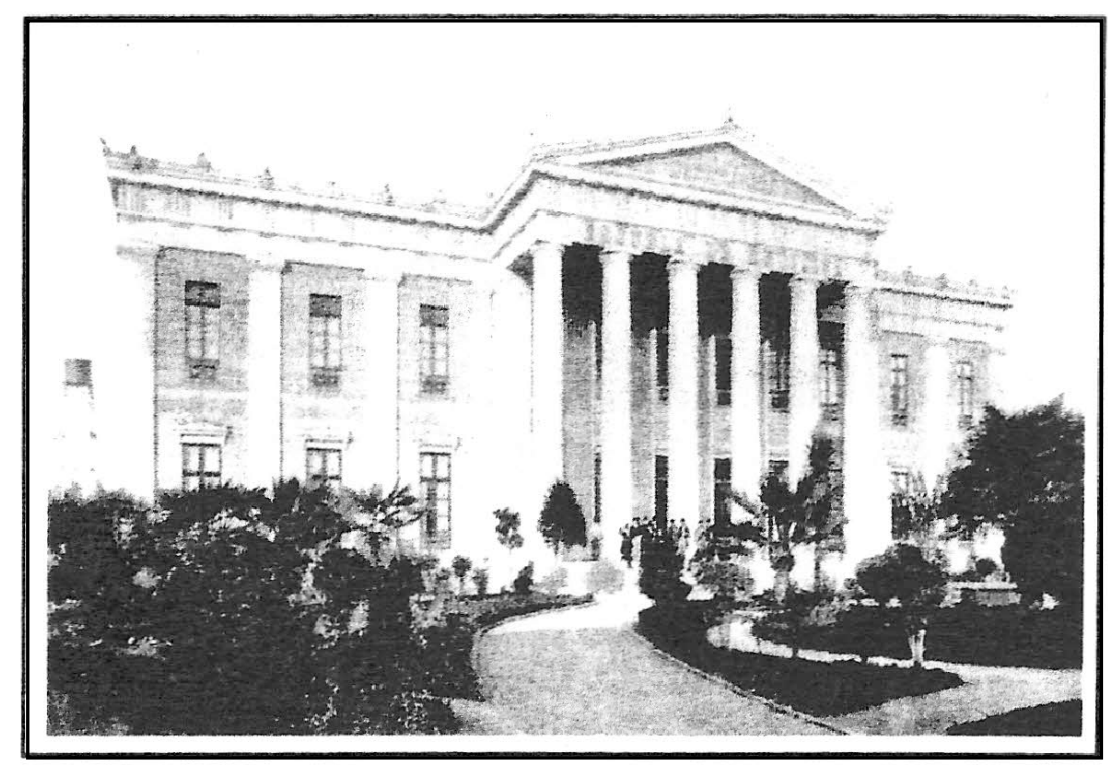


recordamos su estructura hospitalaria, sus Pabellones de Cirugía y Auditorios, semejantes a las fotografías que todavía podemos ver en revistas o publicaciones de esa época.

Su nombre, San Vicente de Paul, discutido en el primer momento, se debió al anti "Lazareto", muy pobre, que fue mandado hacer para los enfermos de viruela agonizantes y fuera de todo tratamiento. El presidente de la época encargó el «Lazareto» a unas monjas de caridad de la congregación de San Vicente de Paul, quienes lo atendieron y aun edificaron una capilla central, que todavía existe y fue declarada Monumento Nacional en 1990, por la belleza de sus vitreaux e imágenes, como la de una antigua Virgen del Rosario. "Sor Briquet», nombre hoy olvidado totalmente, fue la superiora de esta comunidad de abnegación y entrega sin límite.

El Hospital San Vicente tendrá dos secciones: Hospital de Hombres y Hospital de Mujeres. El de hombres se abre a la calle Independencia, a continuación de las edificaciones de la Escuela de Medicina y el de Mujeres hacia la calle Zañartu (calle del Cementerio General). Veremos después que ambas ocupaban gran parte de la manzana de la Escuela, entre Independencia, Santos Dumont, Av. La Paz y Zañartu.

\section{EL HOSPITAL DE HOMBRES}

Su edificación de entrada, por Independencia, es sobria y sencilla. Un patio de entrada antecede la construcción, tiene baldosas y unas bellas palmeras bien conservadas. Una muralla baja de cemento lo cierra hacia la calle, con una reja metálica verde y sus respectivas puertas que siempre están abiertas. La entrada es sólo para personas y no para vehículos.

Se accede al edificio, construido en altura, por una escalinata de cemento de 8 a 10 escalones, con unas sencillas barandas metálicas que combinan con el estilo de la reja de la fachada. El frente estará formado por dos columnas austeras y su frontis con las letras «Hospital San Vicente de Paul». Una imponente puerta de entrada da paso a una galería, a ambos lados con piezas y un corredor de baldosas. Una nueva puerta siempre abierta o con sus batientes libres, da paso a un inmenso patio, descubierto,

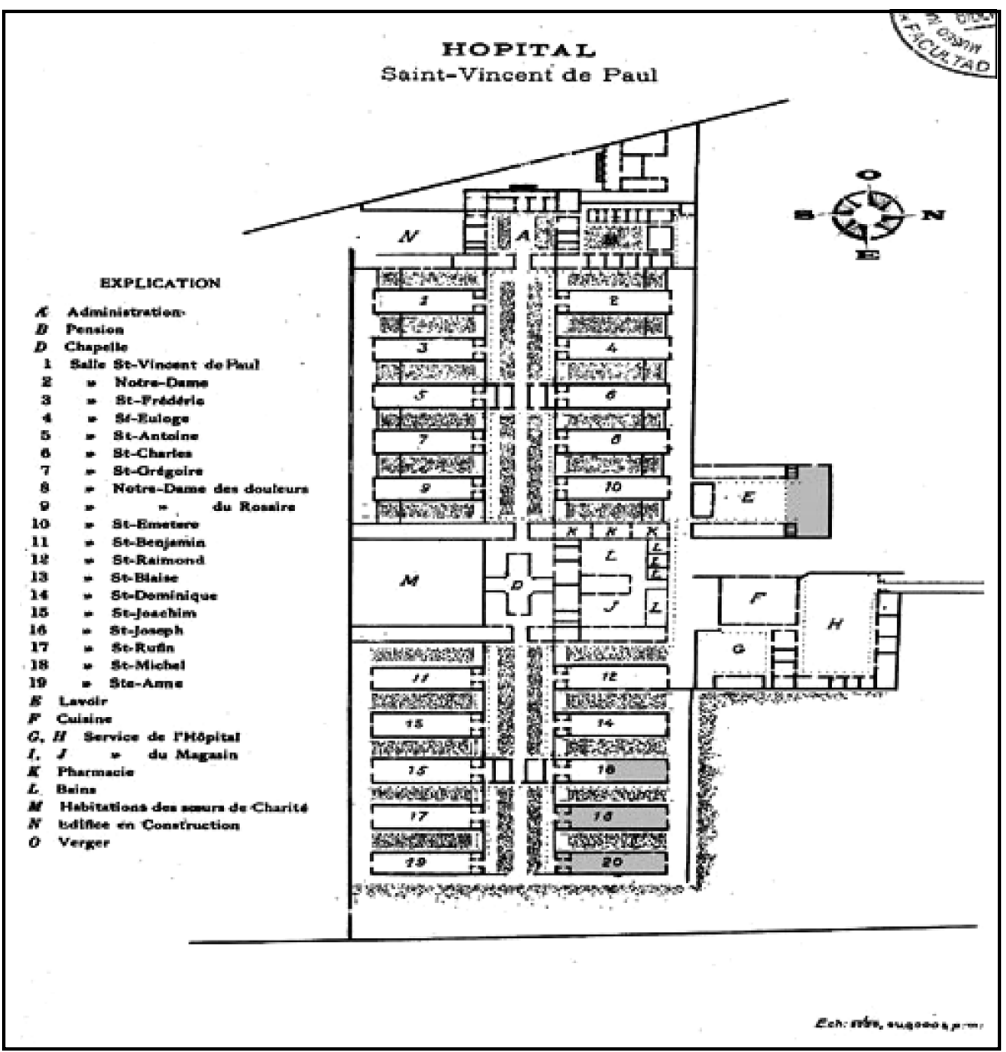




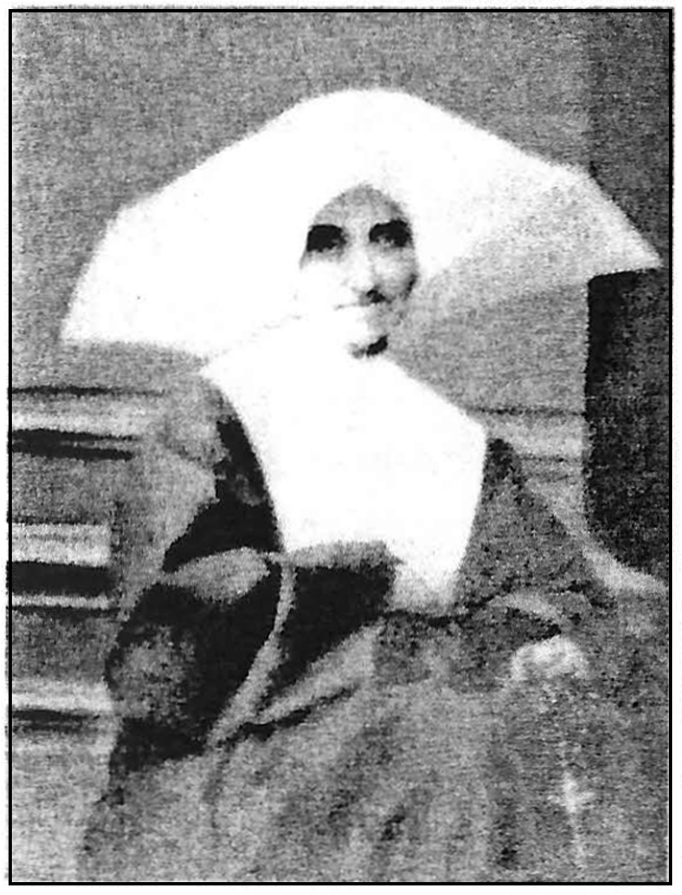

acogedor, con un camino central de baldosas de calle, rodeado de jardines, con pasto y especialmente flores y arbustos.

Un poco más en alto, cierran este patio amplios corredores con sus pilares de madera antigua y baldosas dibujadas lisas rojizas. A ellos salen las puertas de las salas de enfermos. Tres por cada lado, en forma absolutamente simétrica.

Un pequeño pasillo cubierto, del ancho de los corredores dará paso al $2^{\circ}$ patio de igual estructura: jardines centrales, corredores y otras seis salas de enfermos.

$\mathrm{Al}$ fondo de este $2^{\circ}$ patio están las oficinas de la Administración y Farmacia. Entre ellos un pequeño corredor da paso, por otra puerta un poco escondida, a la Capilla del Hospital. Con esto el tránsito del corredor central será interrumpido y será necesario dar una vuelta a las dependencias de Farmacia para llegar al 3er patio. Su estructura será igual, en forma y tamaño, al $1^{\circ}$ y $2^{\circ}$ patio, con su pasillo central, jardines y corredores embaldosados con salidas de las salas de enfermos.

Este patio será más tranquilo y silencioso, más alejado del tráfico y movimiento del $1^{\circ}$ y $2^{\circ}$. También tendrá 3 salas por lado para la atención de los enfermos de sexo masculino.
Las salas tienen sus respectivas placas, con sus nombres a la entrada de cada una. Son todas simétricas e iguales, a la derecha de la puerta de entrada. Casi todas las salas tenían nombres de Santos: «San Antonio», "San Federico», «San Gregorio», «San Emeterio», etc. Según costumbre de la época, en el Hospital de Mujeres, en cambio, tienen una distribución numérica: «Sala No1», «Sala $\mathrm{N}^{\circ} 2$ », «3», «4», «5», seguramente producto de una administración más laica.

A la entrada de cada sala había dos pequeñas piezas, para enfermos más graves, de aislamiento, o bien ocupadas como salas de médicos, escritorios o reuniones. Un sistema de dos puertas de batientes, con vidrios gruesos, que podían abrirse ampliamente para el paso de las camillas, servían de aislamiento para el frío del invierno y el calor del verano.

Las salas, muy grandes y con su techo muy alto, permitían 25 a 30 enfermos cada una. Con sus veladores metálicos y un corredor central que ocupaba un espacio tan amplio como el ocupado por las camas. Catres metálicos pintados de blanco. Tenían grandes ventanales que podían ser abiertos para la ventilación, por un mecanismo de cordeles que permitían la iluminación y ventilación. Los ventanales, bien altos, no permitían ver hacia fuera de la sala. En el pasillo central había una o dos estufas, a leña o carbón para la calefacción, tan necesaria en los días de invierno.

Cada sala tenía su personal, de empleados, practicantes y enfermeros. Las enfermeras universitarias, muy escasas en esa época, tomaban varias salas o a veces había una sola por cada Clínica.

La superficie ocupada por estos tres patios del Hospital de Hombres, era muy grande, llegando las últimas salas casi hasta la Avenida La Paz. Una línea de tren, ya abandonada quedaba en el límite entre el Hospital de Hombres y el de Mujeres. Parecía un ferrocarril en miniatura, con sus carritos para transportar leña, carbón o ropa, desde los servicios básicos de cocina y lavandería que había en la parte posterior del edificio, en otras construcciones.

En el $2^{\circ}$ patio, hemos dicho, estaba la Capilla del Hospital, un poco oculta entre Farmacia y Administración. Muy célebre hoy, había sido construida por las monjas en el tiempo del Lazareto y con la ayuda de celebres arquitectos de la época. Por la belleza de su construcción, las 


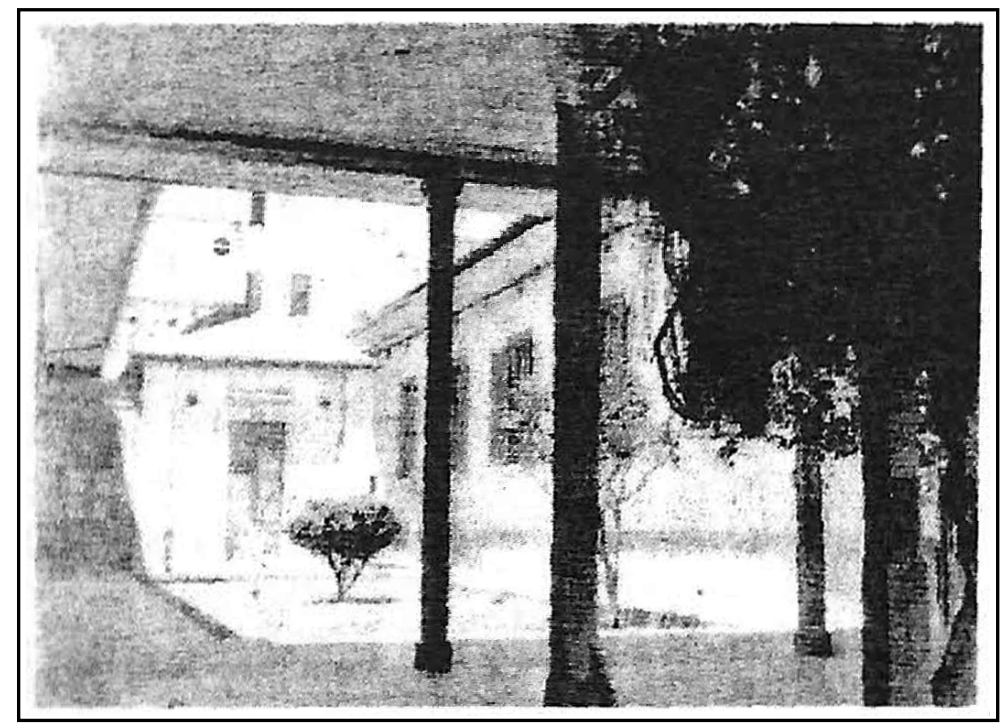

imágenes y sobre todo la calidad de los vitreaux, la declararon Monumento Nacional en 1990. La capilla no formaba parte de la vida del hospital. Siempre cerrada y de difícil acceso, sólo se abría para alguna misa especial o para un funeral importante. No era habitualmente visitada por los enfermos y menos por los médicos. En los años de estudiante y después de médico, con o sin delantal blanco, recuerdo sólo haber entrado una o dos veces, por alguna ceremonia. Las monjas sí cuidaban de ella.

La asistencia religiosa de los enfermos estaba a cargo de unas «monjitas» que quedaban todavía de la antigua congregación. Solícitas acudían a las necesidades personales de los enfermos. Sus caras permanecían plácidas, juveniles, a pesar de sus años, detrás de las grandes "tocas», con sus alas impecablemente blancas. Con poca responsabilidad directa o nula en la asistencia de los enfermos, se paseaban dignamente por los comedores y salas, repartiendo paz y preocupación por los enfermos más graves o inválidos. Eran las encargadas de avisar al "Capellán», único para todo el hospital, de alguna confesión o extremaunción para algún enfermo que lo necesitaba.

El Capellán era un hombre muy especial, de baja estatura y muchos años. Se movía con rapidez y marcha ruidosa, de un lugar al otro del hospital. Sus mejillas enrojecidas lo mismo que su nariz, hizo que un estudiante ocurrente y mordaz le pusiera el sobrenombre de "Cebollita», con el cual se le conocía. Siempre aparecía ante un enfermo grave o cercano a su muerte. Además, ya un poco sordo, sus confesiones y consejos para la otra vida eran oídos en toda la sala.

\section{EL HOSPITAL DE MUJERES}

Entre el $2^{\circ}$ y 3 er patio, frente a la parte posterior de la Farmacia, atravesando esos pequeños rieles antiguos que hemos descrito, había una puerta metálica y una gran muralla de ladrillos y cemento. La puerta, estrecha de más o menos metro y medio de ancho, para dar paso a las camillas, permanecía plegada, abierta, durante todo el día. Una gruesa cadena y candado, también grande, la cerrarían durante t oda la noche. Sólo el «Rondín» de la noche tendrá la única llave y autorización para abrirla. Este era el único acceso al Hospital de Mujeres desde el Hospital de Hombres. Por este lado su construcción aparecía como una construcción posterior o apéndice del Hospital de Hombres.

La entrada principal sin embargo era por la calle Zañartu. Más o menos en la mitad de la cuadra había un gran portón de madera, doble, cuyas puertas estaban totalmente abiertas en el día. Varias gradas de cemento daban acceso a una edificación más alta y a una nueva puerta de madera y vidrio que permanecía abierta, o cerrada a voluntad. Así se entraba a un recinto con las oficinas para la admisión.

A la mano izquierda estaba la Clínica de Ginecología del Profesor Juan Wood. Esta ocupaba toda el ala izquierda del edificio, con sus salas de atención, 
salas de hospitalizadas, oficinas y pabellones quirúrgicos independientes. Todo ordenado con la estrictez y privacidad, aun para médicos de otros servicios, propia de la personalidad y mente extranjera del Profesor Wood.

A la derecha, en cambio, después de un corto pasillo, se salía a un gran patio central, más bajo que la edificación, con jardines, flores y arbustos, semejante al del Hospital de Hombres. Un corredor en alto, con sus pilares de madera antigua, lo cerraba hasta encontrarse con el ala izquierda.

En este lado había sólo dos salas de enfermas, más pequeñas, de más o menos 20 camas cada una: «Sala $\mathrm{N}^{\circ} 1$ », de la Clínica del Profesor Prado Tagle y «Sala $\mathrm{N}^{\circ} 2$, , del Profesor de Cirugía, paralelo, Profesor Álvaro Covarrubias. El resto del ala estaba ocupado por las oficinas, el Auditorio y Pabellones Quirúrgicos de la misma Cátedra.

Por un pequeño corredor se pasaba al otro patio, donde estaban las Salas de Rayos y el Laboratorio Central.

Frente a ellos estará las oficinas de la Cátedra, Auditorio y Pabellones de Cirugía del Profesor Vargas Salcedo, más una sala de hospitalización. Así las dos Cátedras de Cirugía estarían en el sector del Hospital de Mujeres. Dos salas más de mujeres a continuación de la Clínica del Profesor Wood, completarían las 4 salas de Cirugía de Mujeres. Así llegaríamos al paso hacia el Hospital de Hombres, con su puerta de fierro, su cadena y su candado, abierta sólo en el día.

El personal de atención de enfermos eran hombres para los hombres y mujeres para el sector mujeres. Los enfermos sólo podían permanecer en sus respectivos sectores.

En la noche los médicos de urgencia para pasar al sector de mujeres, debían solicitar la llave al rondín y esperar que abra y cierre, hasta atender el «llamado».

\section{ESPECIALIDADES MÉDICAS}

Las especialidades médicas eran Urología, sólo de hombres, en el 3er patio, con salas y pabellones independientes atendidos por el Profesor Bisquert y Coots. La especialidad en mujeres correspondía al servicio de Ginecología.

Dermatología tenía una sala de hospitalización para hombres en el 3er patio, atendida por el
Profesor Prunes y sus ayudantes. Sus enfermos con enfermedades de piel, poco conocidas en ese tiempo, muchas atribuidas a la sífilis tan frecuente en esos años. Era como una "Isla» aislada del 3er patio. La mayoría de sus enfermos eran atendidos en el policlínico o consultorio externo.

Lo mismo sucedía con los enfermos de oídos, nariz y garganta que no tenían camas de hospital y su servicio de atención ocupaba un sector a la izquierda de la entrada del hospital. Su Profesor Dr. Castro Oliveira y sus ayudantes, examinaban ahí sus enfermos y hacían la docencia de la especialidad.

Neurología tenía la primera sala del 1er patio de hombres, a la derecha. Neurología era una especialidad muy importante en ese tiempo gracias al prestigio de sus profesores tales como Orrego Luco, Lea Plaza, Brinck. Hombres de gran capacidad diagnóstica y talento personal. Sin embargo sus enfermos se hacían crónicos con sus hemiplejias, parálisis, etc., sin una esperanza terapéutica en esos años. A veces se los veía tomando un poco de sol y luz, contemplando los jardines del 1er patio, en un banco verde colocado a la entrada de su sala. Todo esto antes del gran desarrollo de la Cirugía y la Kinesiología actual.

\section{ADMINISTRACIÓN Y FARMACIA}

Administración y Farmacia eran los dos únicos servicios "centralizados», al servicio de todo el hospital, sin diferenciación de Cátedras.

La Administración dependía de un Director y un Consejo de Profesores. Sin embargo el Director era el responsable total de la organización del hospital y de los servicios comunes: Alimentación, Abastecimiento, Lavandería, Farmacia y empleados de servicio. El pago de sueldos, su confección y contabilidad eran responsabilidad de la Escuela de Medicina y eran repartidos en las Cátedras.

Recuerdo al «Señor Miquel» quien llegaba a las 4 ó 5 de la mañana y estaba informado de todo. De personalidad muy fuerte. Era temido aun por los profesores, quienes preferían enviar a sus Jefes de Clínica para tratar asuntos de administración, cambios de personal, problemas del edificio, mobiliario, etc.

Mi experiencia personal cuando tuve que tratar con él, ya como Jefe de Sala o bien al conseguir cosas 
para la Sección de Cardiología en formación, descubrî́ que atendía «muy bien» si uno pedía una entrevista antes de la 8 a.m. y llegaba puntualmente a ella. Su trato era totalmente diferente más tarde a las 11 ó 12 . Parece que le gustaba premiar a los «madrugadores» que consideraba «más trabajadores» según su sistema.

El otro servicio centralizado que servía a todo el hospital con sus cátedras era Farmacia. Una Farmacéutica y sus ayudantes, atendían todos los despachos de recetas, sueros e insumos médicos de cada sala del hospital. Su labor eficiente era poco valorada y se recibía como algo natural, responsable y eficiente.

El lugar donde funcionaba, es el que hemos descrito en el hospital de hombres, con una sola ventana abierta que conectaba con el exterior. A nadie se le ocurría pasar a su interior.

En ese tiempo había muchas recetas como jarabes o píldoras-obleas, que debían ser preparadas prolijamente con sus balanzas y métodos manuales. Todo funcionaba perfectamente, como si fuera algo muy natural.

\section{SERVICIO DE URGENCIA Y PENSIONADO}

El frontis del Hospital, hacia la calle Independencia, era seguido por dos construcciones unidas entre sí, ocupando el resto de la manzana hasta llegar a Santos Dumont.

Primero el Servicio de Urgencia, con su amplia entrada para subida y bajada de las ambulancias, que dejaban a los enfermos justo en la puerta y hall de distribución de las camillas de los enfermos agudos, que necesitaban ser atendidos de inmediato.

El otro edificio, con su propia entrada era el Pensionado. Una gran casa de 2 pisos, con piezas en ambos pisos, para la hospitalización de los enfermos privados, que debían pagar su atención. Son clientes generalmente de los médicos del hospital que se atienden en forma particular, con su propio médico. Siempre está completo, debido a la escasa existencia de Clínicas Privadas en esa época.

En el Servicio de Urgencia, los enfermos vienen de distintos lugares, tienen enfermedades agudas o heridos que requieren una atención de inmediato. Tomados sus datos son pasados a los boxes de Urgencia, donde está avisado el médico para que haga su diagnóstico y tratamiento. Puede consultar a otro médico o al Jefe de Turno para resolver un tratamiento. Los boxes de atención son separados por pequeña cortinas, con una camilla de examen cada una y una pequeña escalera de tres peldaños para subirse a ella. Un auxiliar ayuda a sacarse la ropa y el médico o el interno son avisados de inmediato. Todo es muy rápido y expedito. Todo enfermo se supone complicado para llegar a la urgencia del Hospital. Los enfermos o auxiliares, sin embargo son muy hábiles para distinguir una verdadera gravedad, de una reacción de "teatro" emocional. "Doctor, un enfermito en examen» es el llamado y uno no debe averiguar nada más, e ir de inmediato al box de atenciones.

En el primer tiempo de "novato", que uno no tenía ninguna experiencia en enfermos con un dolor agudo o una herida sangrante, era un momento terrible. Como que lo llamaban a dar examen. Luego aprendería los diagnósticos más frecuentes y sería capaz de hacerse ayudar por el médico encargado sin vergüenza de su ignorancia.

De todas maneras para los casos más difíciles u operatorios estaba el médico Jefe de Turno. Autoridad máxima que toma la decisión. Su actuar con la experiencia de años, siempre será una enseñanza para mí. Su docencia es el actuar y con su autoridad decide el diagnóstico final y el tratamiento. Si hay operación se pedirá el pabellón y un equipo médico de ayudantes se formará a la primera orden. Todo funciona como una máquina en marcha, sin más comentarios.

Para el Interno (médico aún no recibido o recién recibido), será una experiencia fantástica. Luego aprenderá que no todo dolor abdominal es una apendicitis y operación. Más de una vez, por no preguntar a la muchacha joven por sus reglas confundirá la apendicitis con un dolor de embarazo. El ayudante con más experiencia lo descubrirá y embromará al Interno diciendo: «su apendicitis era con patitas». Así son las crónicas propias de los Servicios de Urgencia. El interno irá poco a poco aprendiendo a adquirir seguridad en los diagnósticos y en saber qué hacer ante una emergencia. Los meses de turnos de 3 horas y las noches de guardia cada 5 ó 6 días lo irán formando en esta medicina que no se puede enseñar en los auditorios.

Recuerdo con cariño a varios Jefes de Turno, que sin título de Profesor, eran hábiles cirujanos 
que podían resolver todos los problemas y enseñaban con el quehacer. Lo mismo los médicos ayudantes, inagotables en el trabajo, siempre estaban dispuestos a enseñar, a veces con alguna broma poco amable pero con alto espíritu de docencia y orgullo de ser capaces ante el problema del enfermo. Recuerdo meses de trabajo y enseñanza junto a dos cirujanos recién recibidos pero ya con años de experiencia en servicios de urgencia. Estos fueron Luis Figueroa Geisse y Barrera, cuyo nombre no lo recuerdo porque a él siempre le gustaba que lo llamaran sólo "Dr. Barrera». Muchas enseñanzas tengo que agradecer al profesor Adolfo Escobar, Jefe de Turno, quien fuera después un excelente cirujano de corazón. Muchos otros Jefes de Turno, que sin pertenecer a la docencia de las Cátedras, eran excelentes docentes para nuestra formación.

Estos turnos eran duros de trabajo diario, que se sumaba a los del «internado» y atención de las salas, con los enfermos hospitalizados durante el día.

Uno prefería los turnos en la Posta del Servicio de Urgencia, de 6 a 9 P.M. en la tarde, porque dejaba libre el día, para sus obligaciones con sus enfermos hospitalizados, reuniones clínicas y actividades docentes, que se realizaban fundamentalmente en las mañanas. Los Profesores y Jefes de Clínica sólo estaban en las mañanas en el Hospital. De modo que las tardes eran tranquilas, para llevar las historias de los enfermos, solicitar sus exámenes y atenderlos en sus necesidades personales y familiares. Siempre recuerdo esas conversaciones íntimas, dando consejos, nosotros jóvenes sin experiencia de 25 a 30 años, a hombres o mujeres de 40, 50 o más, casados y con hijos, recibidos con tanto cariño y gratitud. Ahí aprendí esta verdad: que la medicina «ayuda», a veces «sana», pero siempre debe «acompañar y consolar». Los días de trabajo, con turnos en el Servicio de Urgencia en las tardes y a veces, cada cuatro o cinco días una noche completa, resultaban muy pesados. Es cierto que el día post noche de turno era libre, de 6 a 9 PM para recuperarse y dormir.

A pesar de la juventud y el entusiasmo por querer aprender se llegaba al cansancio máximo, como una aventura que recuerdo de los tiempos de «internado». Llamado así por la ocupación de todo el día pero sin alojamiento, excepto cuando se trabajaba en el Servicio de Urgencia. Una noche que continuaba al turno de 6 a 9 PM., el Jefe de Turno me autoriza para que vaya al centro, «coma algo» $\mathrm{y}$ "descanse para seguir después la noche».

Tomo mi autito, el D.K.W. y voy a la Plaza de Armas, me estaciono frente a uno de los pasajes, en su costado sur, está todo vacío, donde sirven comidas rápidas. Me relajo y se me despierta un «apetito bárbaro» y pido un bistec, con papas fritas y un huevo. ¡Me siento libre de toda responsabilidad! Después de comer tomo de nuevo el auto para regresar al Servicio de Urgencia del Hospital, en Independencia. Voy despacio un poco consciente de mi cansancio. Antes de llegar a la calle Santos Dumont, siento un golpe, despierto y me veo debajo de un camión en su parte trasera. Un ruido de agua cayendo me indica que he roto el radiador. Explicaciones con el camionero, cuyo camión no ha sufrido nada. Puedo llegar hasta el Hospital y convencerme que el cansancio y la fatiga me podrían haber costado la vida. 